Supplement of Solid Earth, 10, 1833-1855, 2019

https://doi.org/10.5194/se-10-1833-2019-supplement

(C) Author(s) 2019. This work is distributed under

the Creative Commons Attribution 4.0 License.

(c) (1)

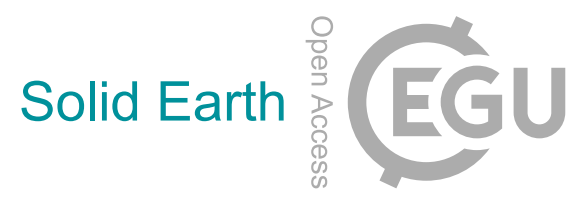

Supplement of

\title{
Full-waveform inversion of short-offset, band-limited seismic data in the Alboran Basin (SE Iberia)
}

\section{Clàudia Gras et al.}

Correspondence to: Clàudia Gras (gras@icm.csic.es)

The copyright of individual parts of the supplement might differ from the CC BY 4.0 License. 


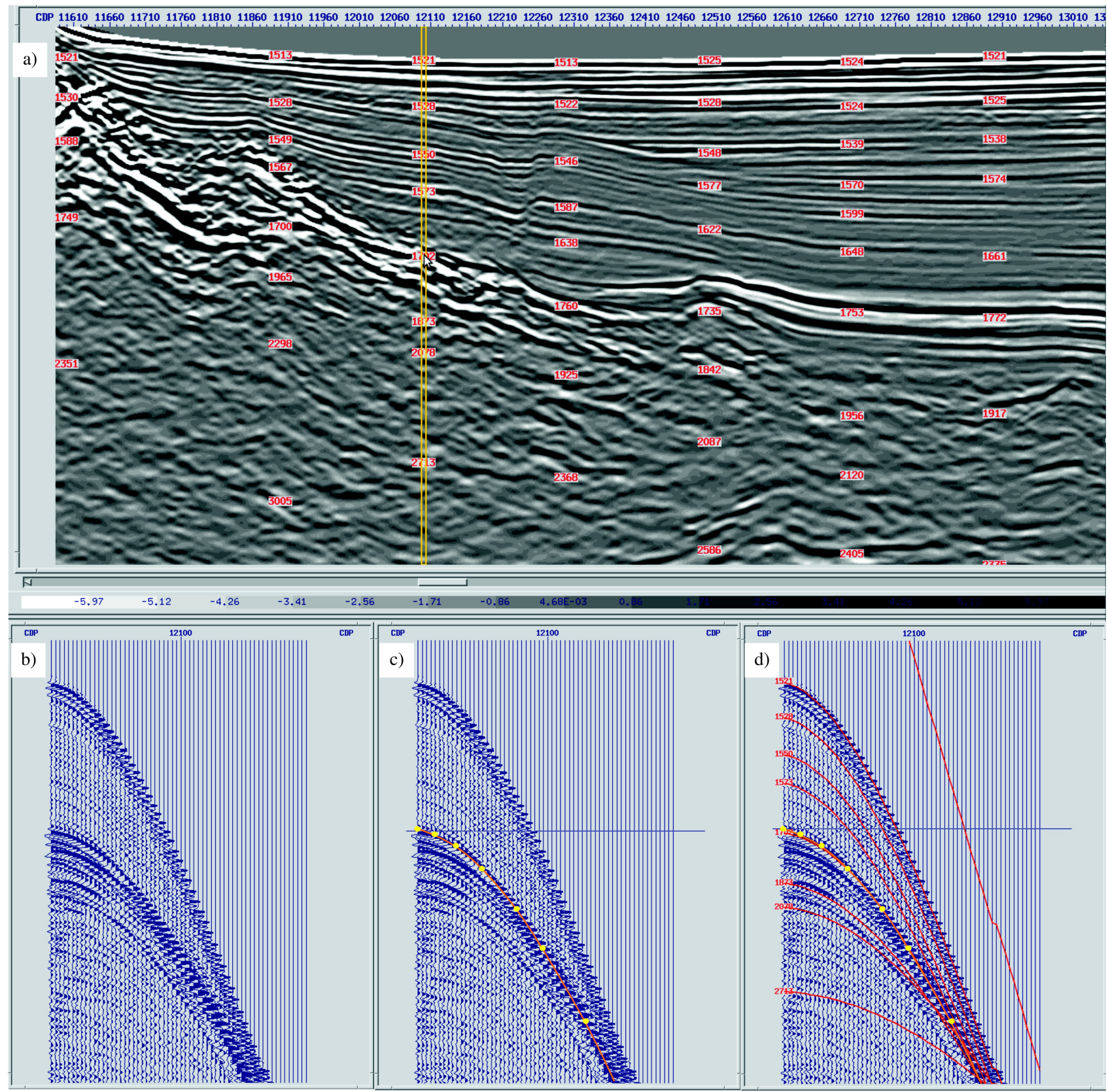

Figure S1: Reflector picking procedure. Processed stack image of a section of the seismic profile (a) showing the location of the CMP gather that is plotted with (c), (d) and without (b) the TOB reflection travel times (yellow circles) used as input for the TTT. The TOB is a bright continuous reflection on CMP gathers. The arrow in (a) and horizontal line in (c), (d) indicate the position of the TOB reflection in the stack image and CMP gathers. Red lines in (d) correspond to velocity parabolas that are used as a velocity control during the reflector picking. 